\title{
Microscopy to Evaluate Retting of Flax and Flax Fibers
}

\author{
D.E. Akin and D.S. Himmelsbach
}

Russell Research Center, ARS-USDA, PO Box 5677, Athens, GA, 30604

Flax (Linum usitatissimum L.) is the source of fibers for textiles (i.e., linen), composites, and specialty paper. Fibers are produced in the bast region of stems, and they are separated from nonfiber components by a microbial process called retting. Currently flax is field-retted, which results in inconsistent quality fibers, and considerable research has been done to find an alternative. Our current research has focused on the use of enzymes plus chelators to ret flax. The use of microscopic methods, including light and electron, mid infrared (MIR) microspectroscopy, histochemistry, and UV absorbance microspectrophotometry, have elucidated structural and chemical relationships and led to improvements in the enzyme-retting process.

The high levels of non-methoxylated pectin and calcium in the epidermis of the stem, along with the cuticle, form a formidable barrier for entry of enzymes to potential substrates for retting. The inclusion of calcium chelators, such as EDTA, improves the effectiveness of pectinases [1] in commercial enzyme mixtures for separating the cuticularized epidermis from fibers (Fig. 1a,b). MIR mapping [2] of unretted flax indicates that esterified pectins and pectin salts, including calcium-stabilized pectin, often both predominate in the parenchyma/epidermal region (Fig 2a,b). These images suggest a reason for chelator activity and also provide a means of assessing effectiveness.

Data indicate that pectinases alone appear sufficient to separate fibers [2], although other enzymes could improve the fiber properties. The commercial pectinase-rich mixtures used often contain cellulases. Use of high levels or long incubation times result in loss of fiber strength. Research indicated that cellulases in mixtures initially attack fibers at specific regions called fibernodes, thereby weakening fibers [3]. Polarized microscopy indicated that dislocations in fibers, likely fibernodes, are particularly susceptible to cellulases. Strength tests revealed blunt ends for broken fibers, indicating these dislocations are the weak points; cellulase tends to exacerbate the weakness.

While lignin is often considered a negative influence on retting due to its general recalcitrance in plants, microscopic results from histochemistry, UV absorbance, mid infrared microspectroscopy all show that lignin is primarily confined to the innermost, core tissues. The fibers contain non-uniform sites of lignin in the cell corners. Results indicate that lignin does not pose a major limitation for fiber separation, particularly when mechanical cleaning follows enzyme retting. Therefore, the degradation of lignin is not necessary for retting, and any substantial amounts of lignin in fiber suggest that the inner core tissues are present as contaminants.

\section{References}

[1] G. Henriksson et al., Textile Res. J. 67 (1997) 829.

[2] D. Himmelsbach et al., J. Sci. Food Agric. 82 (2002) 685.

[3] D.E. Akin et al., Textile Res. J. 72 (2002) 27.

[4] J.D. Evans et al., J. Biotechnol. (2002) 223. 


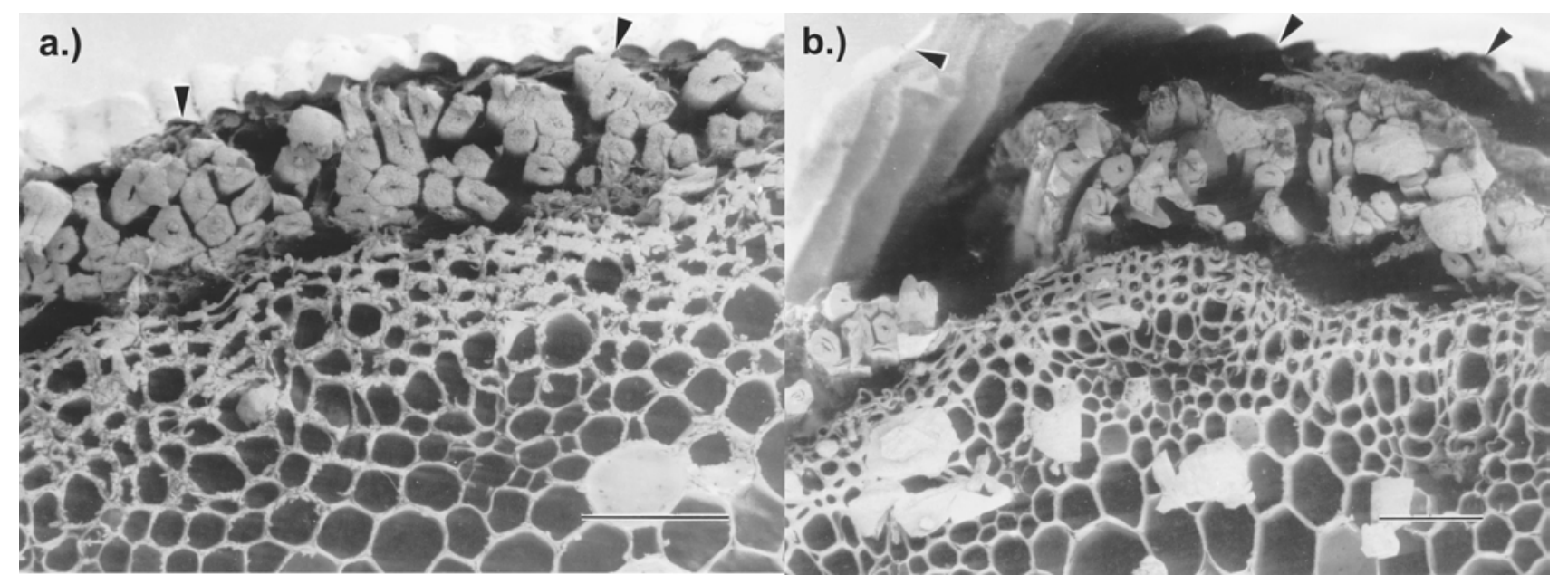

Figure 1. Scanning electron micrographs of flax stems retted with a pectinase-rich enzyme mixture only (a) or with pectinase plus EDTA chelator (b) for $8 \mathrm{~h}$. Fibers are beginning to separate from non-fiber tissues with enzyme alone, but inclusion of chelator with enzyme effectively separates fibers and fiber bundles from the cuticularized epidermis (arrows). Bar equals $50 \mu \mathrm{m}$.

a.)

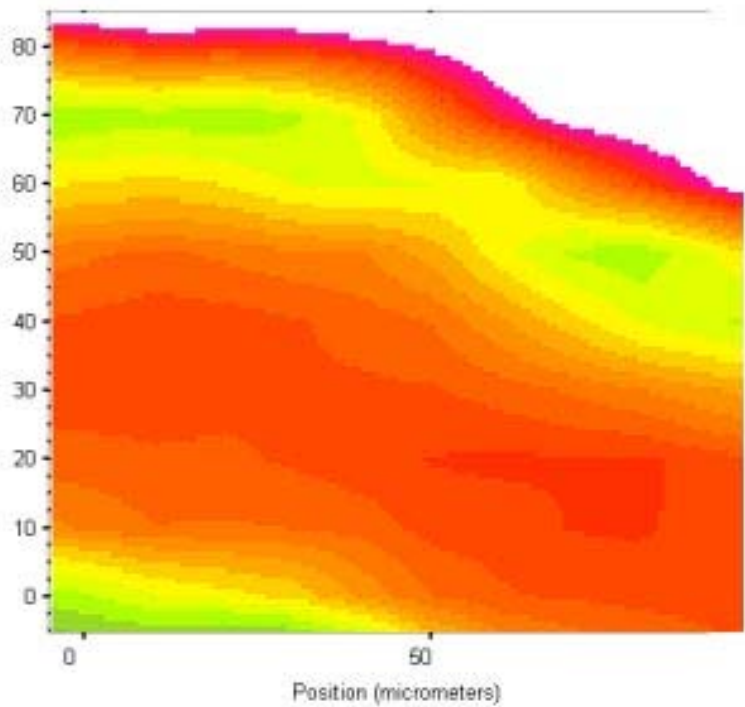

b.)

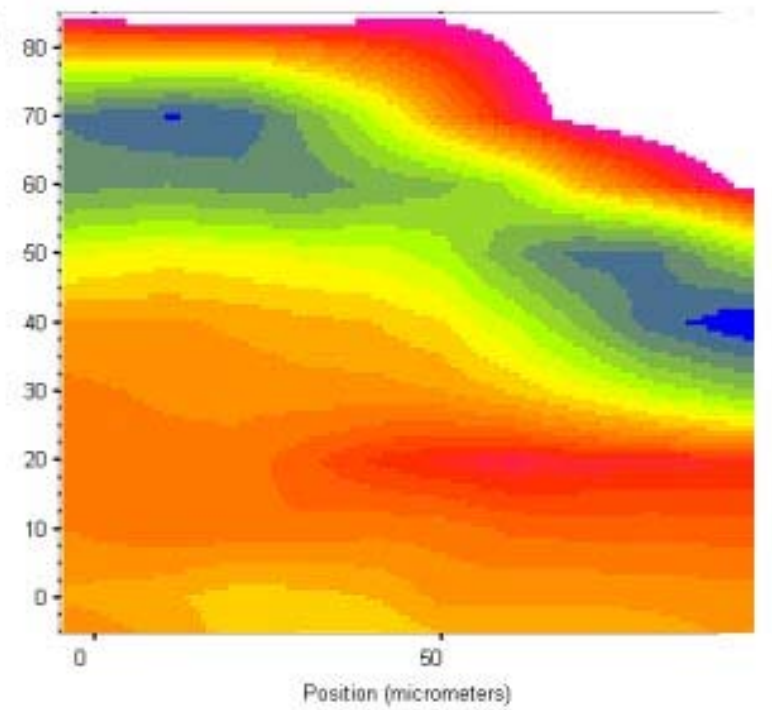

Figure 2. Infrared maps of $6 \mu \mathrm{m}$ thick cross-section of flax stem showing locations and intensity of: (a) esterified pectin from $\mathrm{C}=\mathrm{O}$ band at $1734 \mathrm{~cm}^{-1}$ and (b) pectate salts from $\mathrm{COO}^{-}$band at $1608 \mathrm{~cm}^{-1}$. Intensity increases in the order: red $<$ orange $<$ green $<$ blue. Higher intensities for absorbance at these wavenumbers are in the parenchyma/epidermis region, and results in (b) especially show the tendency for calcium-stabilized pectin in this region. 